\title{
Challenges of Producing Quality Construction Steel Bars in West Africa: Case Study of Nigeria Steel Industry
}

\author{
Sanmbo Balogun, David Esezobor*, Samson Adeosun, Olatunde Sekunowo \\ Department of Metallurgical and Materials Engineering, \\ University of Lagos, Nigeria 23401 \\ *Corresponding Author, contact: esezobordave@yahoo.com
}

\begin{abstract}
The production of quality high-yield reinforcing steel bars continues to receive attention from researchers across the globe due to its importance and contribution to a country GDP. In most of the developing countries, particularly Nigeria, empirical studies have shown that bars produced through conventional rolling requires appropriate modification of its chemical composition in order to obtain the desired mechanical properties such as strength. However, the high cost factor involved in composition adjustment makes such approach unattractive. Rather, the application of the combination of systems of controlled rolling and controlled cooling proves to be the best option. This system however, requires some variations in processing parameters to suit individual plant production peculiarities. In this paper attempt is made to study the production challenges and opportunities the steel millers are facing in Nigeria. Previous works in this area are also reviewed with a view to charting the way forward. Experimental studies and process monitoring were carried out at some designated rolling mills in Nigeria.
\end{abstract}

Key Words: Mild steel, bar, strength, controlled rolling/cooling, thermo-mechanical, conventional-mill,

\section{INTRODUCTION}

Despite stiff competition from other materials, steel remains one of the most important engineering materials [1]. Indeed the quantum of its consumption per head forms the basis for measuring the level of a nation's technological advancement. 
Steel exhibits a wide range of mechanical characteristics of which the strength factor is the dominant property. Engineering strength is however, evaluated in terms of yield strength $\sigma_{y}$, ultimate tensile strength (UTS), modulus of elasticity (E), percentage elongation and impact strength. Thus, any increase in the strength characteristics of steel will enhance the reliability and durability of the structure/machine in which it is used [2]. Conversely, low strength characteristics often result in short life span of structures, warpage, undesirable deflection and even failure/collapse.

In common engineering applications mild steel, $0.1-0.3 \% \mathrm{C}$ are used in preference to different grades of plain carbon steels. The bars, mostly produced by hot rolling, constitute the bulk (90\% by weight) of all structural steel profiles commonly employed in construction and allied engineering works [3]. Other areas of mild steel application include structural (reinforcements and trusses), automobile (car bodies, transmission shafts etc), plant construction, foundry, agricultural machinery, etc.

A direct correlation exists between steel's microstructures and its mechanical properties [4]. Hence, the development of a relevant structure - property model in steel is therefore, one of the effective methods of improving its mechanical properties [5]. However, appropriate production method needs to be developed to meet increasing global demand for steel bars of superior strength characteristics appreciably at low cost. Empirical analyses of methods of producing hot rolled steel bars indicate a radical departure from the conventional rolling practices. Against the sole dependence on chemical composition adjustment, emphasis is currently placed on the development of relevant structural property that guarantees enhanced strength characteristics. Through skilful manipulation of metallurgical factors, higher strengths are induced in the bar on the basis of better corresponding microstructures developed.

Regrettably, mild steel bars produced in Nigeria and some West African countries particularly Ghana exhibit abysmally low strength characteristics. According to a report [6], the world average specification for high yield steel bar is $460-500 \mathrm{MPa}$. Comparison of other relevant strength parameters with locally produced bars is presented in Table 1.

Table 1. Strength Characteristics Specification Comparison

\begin{tabular}{|l|c|c|}
\hline Strength Characteristics & International Standard (min.) & Nigeria Bars \\
\hline Yield Strength $(\mathrm{MPa})$ & 460 & $250-350$ \\
\hline UTS $(\mathrm{MPa})$ & 600 & $410-500$ \\
\hline Elongation $(\%)$ & $10-25$ & $9-14$ \\
\hline
\end{tabular}


With particular reference to the locally produced bars, the reality of the consequences of the data in Table 1 had always impacted negatively on local steel industry. Risk of failure of structure(s) in which such bars are used is quite high, giving rise to lack of confidence in the quality of locally made bars. This has made the massive importation of the better quality product an imperative. The result is the neglect and underdevelopment of the local steel industry. These are real engineering problems to which an effective solution must be found.

\section{METHODS}

Several experimental studies and process monitoring were carried out at some designated rollingstock (billets, ingots) production plants and rolling mills in Nigeria.

Metallurgical factors investigated include chemical composition, rolling-stock internal soundness (level of dissolved gases, inclusions, sulphur and phosphorus) and rolling process dysfunction factors. The latter encompasses the soaking temperature regime, strain, strain-rate, static and dynamic recrystallisation during rolling and cooling of the rolled product. Basic processing data obtained from these exercises are used in the analysis.

\section{RESULTS AND DISCUSSION}

From the analyses, it was established that the problem of low strength characteristics prevalent in conventional hot rolled steel bars entails two factors namely: metallurgical and process dysfunction.

\subsection{Metallurgical Factor}

Table 2 is a compilation of the average chemical composition of various billets/ingots produced in Nigeria.

Variations of the strain hardening factor parameters in terms of carbon, copper and the Ceq value are presented in Figure 1. The standard deviation for carbon calculated from the data in Table 2 is 0.09 against the acceptable value of 0.05 .

Although, mild steel mostly used for structural purposes contain $0.15-0.30$ percent carbon [7], billet compositions in the range $0.15-0.25$ percent are preferable. The choice of the low carbon level is to prevent embrittlement of the material during strain hardening and the development of undesirable microstructure in the heat-affected zone (HAZ) of such steel bar during welding.

The two metallurgical factors considered in the formulation of the carbon equivalent relation [8] are expressed in equation 1 as: 


$$
C e q=C+\frac{M n}{6}+\frac{C r+M o+U}{5}+\frac{N i+C u}{15}
$$

Thus, for weldable steel, $\mathrm{Ceq} \leq 0.51$ while $\mathrm{Ceq}>0.51$ is indicative of non-weldability [9]. From Figure 1 it can be seen that five out of seven (71.4\%) companies' products tested had $\mathrm{C}_{\mathrm{eq}}$ values in the range $0.51-0.58$ and a standard deviation $\left(\sigma_{\text {Ceq }}\right)$ of 0.05 as against the normal 0.02 . This implies that most locally produced steel bars are non-weldable.

Table 2 Average Chemical Composition of Steel Billet Produced in Nigeria

\begin{tabular}{|l|c|c|c|c|c|c|c|c|c|c|c|c|}
\hline \multirow{1}{*}{$\begin{array}{c}\text { Steel } \\
\text { Producer }\end{array}$} & \multicolumn{10}{c|}{ Elements, \% } \\
\cline { 2 - 15 } & $C$ & $S i$ & $\mathrm{~S}$ & $P$ & $M n$ & $N i$ & $C r$ & $M o$ & $V$ & $C u$ & $F e$ & $C^{*}{ }_{e q}$ \\
\hline Federated Steel & 0.266 & 0.164 & 0.018 & 0.018 & 0.637 & 0.026 & 0.025 & 0.502 & 0.001 & 0.220 & $\mathrm{Bal}$ & 0.40 \\
\hline Sankyo & 0.209 & 0.203 & 0.048 & 0.036 & 0.876 & 0.096 & 0.118 & 0.019 & 0.003 & 0.266 & $\mathrm{Bal}$ & 0.41 \\
\hline Delta Steel & 0.358 & 0.397 & 0.019 & 0.027 & 1.109 & 0.061 & 0.077 & 0.013 & 0.001 & 0.141 & $\mathrm{Bal}$ & 0.58 \\
\hline Major & 0.354 & 0.365 & 0.037 & 0.033 & 0.801 & 0.107 & 0.118 & 0.017 & 0.003 & 0.291 & $\mathrm{Bal}$ & 0.54 \\
\hline Universal & 0.345 & 0.239 & 0.032 & 0.028 & 0.699 & 0.080 & 0.128 & 0.019 & 0.002 & 0.232 & $\mathrm{Bal}$ & 0.51 \\
\hline African Steel & 0.332 & 0.210 & 0.036 & 0.031 & 0.857 & 0.101 & 0.105 & 0.013 & 0.003 & 0.240 & $\mathrm{Bal}$ & 0.52 \\
\hline Nigerian Spanish & 0.376 & 0.062 & 0.042 & 0.005 & 0.587 & 0.034 & 0.024 & 0.014 & 0.011 & 0.223 & $\mathrm{Bal}$ & 0.51 \\
\hline
\end{tabular}

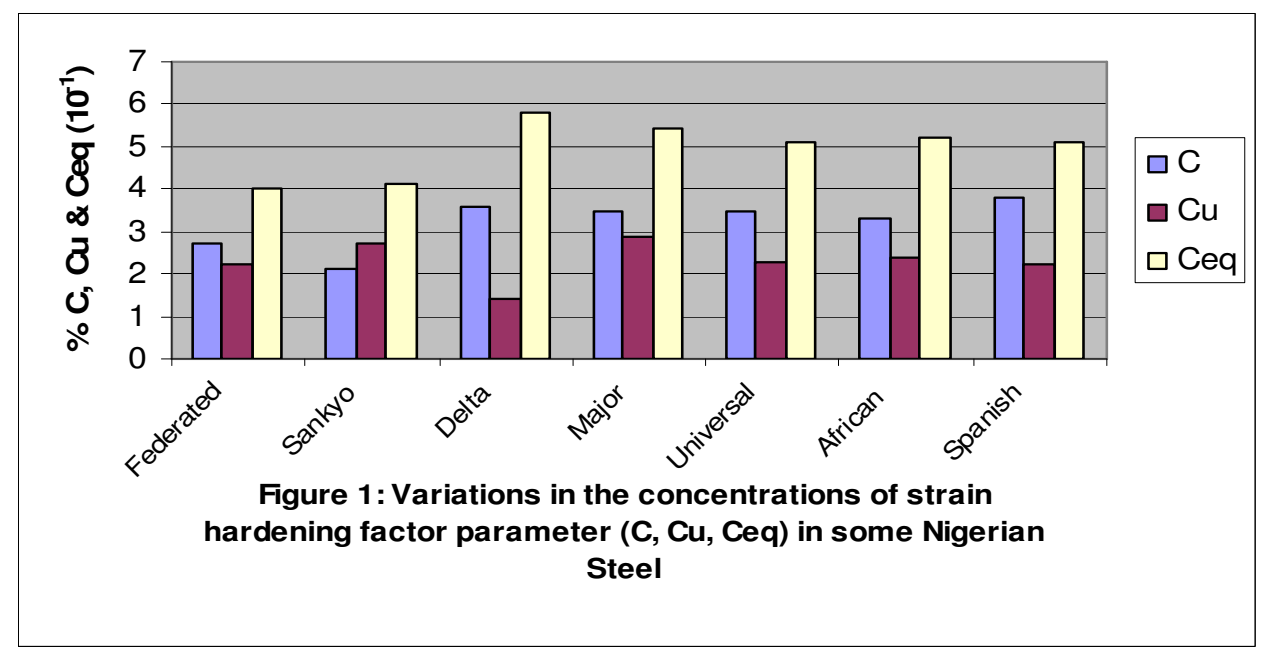

The quality of molten steel depends on the charge characteristics. These include levels of deoxidation, inclusions, slag composition and cleanliness. Sulphur and phosphorus are the two major deleterious elements that must be controlled.

It may be deduced from Figure 2, that all the rolling stocks (except a few) maintain the standard level of concentration of these impurities ( 0.04 max for the grade of steel). 
Deoxidation may be either through oxygen lancing or via the modern practice of slag foaming technique [10]. The usefulness of this method however, depends on the slag composition as steel with high level of dissolved gases particularly oxygen and nitrogen can make the steel behave in a brittle manner [11] if not controlled.

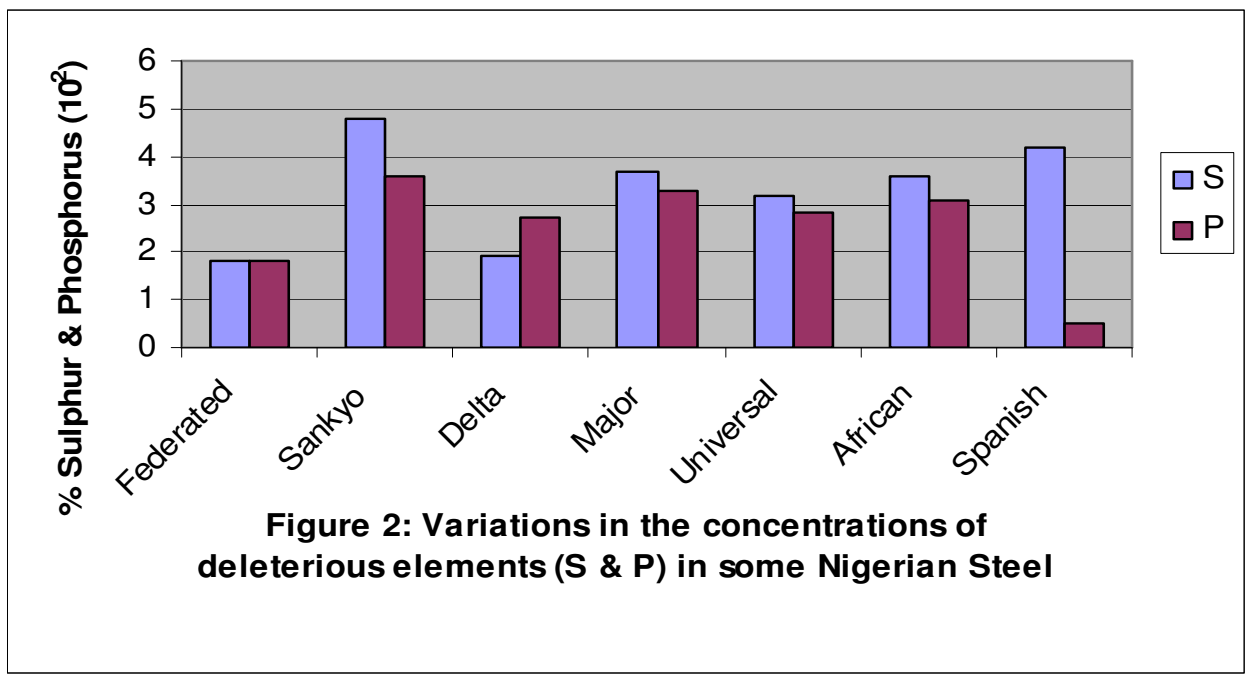

Steel purity entails minimizing the size and frequency of undesirable non-metallic inclusions. It is well established [12] that the presence of small-scale inclusions limits maximum stresses and other desirable mechanical properties of steel. Hence, only a slim allowance is usually considered for trace elements such as zinc, tin and lead. These elements affect negatively the creep strength, ductility, susceptibility to corrosion and workability of mild steel [13].

Obikwelu [14] demonstrated that metallic inclusions largely account for the anisotropic behavior of hot rolled steel bars. These inclusions spread along the rolling direction thus lowering the ductility and toughness. Uniform mechanical properties at any orientation to the rolling direction can be obtained if the inclusions are small and equiaxed or globular. Rapid sensor-based technology or real time analysis of most of the processing parameters can greatly enhance the properties of steel. Table 3 shows the average tramp elements analyzed for local steel making charges in comparison with the allowable values in good quality hot rolled mild steel.

It is evident from the table that most steel plants in Nigeria have high scrap input compared with the use of virgin charges such as direct reduced iron (DRI) and briquettes. This condition can be improved through dilution with substantial amount of DRI or briquettes to give purer steel as in the case of Delta steel. A process route for the production of low carbon, aluminum-killed steels with purity index of $1.5 \mathrm{mg}$ of steel and total oxygen content of $27 \mathrm{ppm}$ have been developed [15]. With optimum control of the melting process, desirable requirements in terms of chemical composition can be achieved through either EAF or BOF route. Based on his work, Breedijk, T. 
[16] has reiterated the fact that the silicon semi-killed BOF remains the best process route for steel meant for concrete reinforcement.

Table 3. Average Tramp Elements in EAF Charges

\begin{tabular}{|c|c|c|c|c|}
\hline \multirow[b]{2}{*}{ Facility } & \multirow[b]{2}{*}{ Type of Charge } & \multicolumn{2}{|c|}{ Tramp Element } & \multirow[b]{2}{*}{$\begin{array}{l}\text { Cleanliness } \\
\text { Status }\end{array}$} \\
\hline & & $\begin{array}{c}\mathrm{Cu}+\mathrm{Sn}+ \\
\mathrm{Zn}(\%)\end{array}$ & $\begin{array}{c}\text { Max. } \\
\text { Allowed }\end{array}$ & \\
\hline Sankyo Ltd, Ikeja & $\begin{array}{l}100 \% \text { Heterogeneous } \\
\text { steel scrap }\end{array}$ & 0.50 & 0.46 & Unsatisfactory \\
\hline U-Steel, Ikeja & $\begin{array}{l}100 \% \text { Heterogeneous } \\
\text { steel scrap }\end{array}$ & 0.46 & 0.46 & Satisfactory \\
\hline Federated Ota & $\begin{array}{l}100 \% \text { Heterogeneous } \\
\text { steel scrap }\end{array}$ & 0.52 & 0.46 & Unsatisfactory \\
\hline $\begin{array}{l}\text { African Steel } \\
\text { Ikorodu }\end{array}$ & $\begin{array}{l}100 \% \text { Heterogeneous } \\
\text { steel scrap }\end{array}$ & 0.47 & 0.46 & Unsatisfactory \\
\hline Delta Steel Warri & $20 \%$ scrap $80 \%$ DRI & 0.28 & 0.46 & Good \\
\hline
\end{tabular}

The cost effectiveness of the EAF or BOF route, however, depends on such factors as scale of operation, cost and availability of raw materials (scraps, highly metalized pellets, etc) and energy. Currently, gas based DRI is more commonly charged to the EAF [17]. This could be attributed to the fact that the former offers higher metallization than the coal based variety and a higher carbon content that can provide chemical energy in the form of "carbon boil" during EAF operation.

Thus, the control of composition within acceptable tolerance limits is a precursor to the production of hot rolled bars that exhibit acceptable strength characteristics. Such specification as published in the British Standard BS 4449 of 1988 is highlighted in Table 4. The data are based on cast analysis of billets meant for the production of reinforcing bars. The values specified have been harmonized with ISO 6935 parts I and II to ensure global application.

Table 4. Chemical Composition of Steel Grades* (BS 4449)

\begin{tabular}{|c|c|c|c|}
\hline Element & $\begin{array}{c}\text { Grade 250 } \\
(\% \text { Max. })\end{array}$ & $\begin{array}{c}\text { Grade 460 } \\
(\% \text { Max. })\end{array}$ & $\begin{array}{c}\text { Deviations } \\
(\% \text { Max. })\end{array}$ \\
\hline Carbon & 0.25 & 0.25 & 0.02 \\
\hline Sulphur & 0.060 & 0.050 & 0.005 \\
\hline Phosphorus & 0.060 & 0.050 & 0.005 \\
\hline Nitrogen & 0.012 & 0.012 & 0.001 \\
\hline
\end{tabular}

* Grades are given in term of the minimum yield strength: Grades 460 are for hot rolled high yield deformed bars while grades 250 are for low yield plain bars. 


\subsection{Rolling Process Dysfunction}

Hot rolling as a shaping method is the plastic deformation at about 0.6 melting temperature of an engineering material. At this temperature range, recrystallisation is spontaneous and the structure is substantially free of strain hardening. Generally, three stages namely, preheating, sequential plastic deformation and finishing are involved.

Preheating of the rolling stock is part of the metallurgical requirements of the process, which is regarded as solution treatment in the austenitic phase. This allows for dissolution of solute precipitates. However, sufficient time is needed to ensure complete homogenization of the structure by diffusion [18]. The dependence of diffusion on temperature, $\mathrm{T}$ and time, $\mathrm{t}$ may be expressed as

$$
\begin{aligned}
& D=D_{0} \exp ^{(-Q / R T)} \\
& X=(D t)^{1 / 2}
\end{aligned}
$$

where, $\mathrm{D}$ is the diffusion coefficient, $\mathrm{D}_{\mathrm{o}}$ is proportionality constant, $\mathrm{Q}$, is the activation energy, $\mathrm{R}$, gas constant, and $\mathrm{X}$, the diffusion distance.

The temperature to which a rolling stock is preheated must be properly controlled in order to avoid the debilitating effect of grain coarsening at high temperature [19]. Most rolling mills in Nigeria do not have temperature-monitoring devices such as thermostats and thermocouples that are usually attached to preheating furnaces and rolling lines respectively. This deficiency impacts negatively on the quality of the local rolled products. Emphasis is currently placed on synchronization of the continuous caster with down-stream mill to avoid the need for reheating before rolling [20]. This results in substantial reduction in the cost of energy and weight-loss due to scaling. However, this does not preclude the imperative of inter-stand temperature monitoring during rolling.

The various metallurgical phenomena namely strain, strain hardening, static and dynamic recrystallisation occurring during the sequential plastic deformation of rolling stock are influenced by the series of grooves on the rolls. Roll-pass design is thus a major factor in the success or otherwise of any rolling process [21]. For desirable goals to be achieved, careful handling is required to ensure proper property changes of steel during deformation at varied loads, temperature and composition. Roll-pass design is also known to have a significant effect on the flow stress of the metal [22]. The design that accomplishes rolling of bars within limited number of passes is usually considered [23].

Principal dynamic recovery in hot working is the softening mechanism for the work hardening of rolling stock occurring through dislocation climb and cross-slip. There is a fundamental relationship between plastic strain rate and average dislocation velocity [24]. Thus, the extent of 
plastic deformation a material undergoes is proportional to its dislocation density [25]. Therefore, in hot working where dynamic recovery is not possible through dislocation climb and cross-slip, dynamic recrystallisation occurs as the softening mechanism. These processes occur continuously to varying extents depending on temperature and dwell time throughout the rolling process.

The finishing operation refers to activities aimed at conferring desired property characteristics on rolled product via microstructural evolution. Both the structure and the corresponding mechanical properties are determined by the rolling temperature and the cooling pattern [26]. Apart from the conventional air-cooling approach, a host of other innovative methods have been developed to meet the ever-increasing demand for rolled products with superior strength characteristics.

It may be deduced from the foregoing that, microstructure and mechanical properties of hot rolled steel bars are determined by such factors as the chemistry of the rolling stock, rolling temperature and the cooling pattern employed. In order to obtain bars of adequate strength levels, all these parameters must be constantly monitored and controlled.

\section{CONCLUSION}

The reality, causes and consequences of low strength characteristics exhibited by mild steel bars produced in Nigeria have been analyzed. It would appear that improved processing method is the most effective and efficient panacea to the problem. Innovative processing methods that integrate all critical factors namely chemically sound rolling stock, controlled thermal variation during rolling and controlled cooling are imperative. These could be complemented by installing relevant process-variables monitoring devices.

\section{ACKNOWLEDGEMENT}

The authors acknowledge the technical assistance from Federated Steel Mills Ota and Universal Steels Limited Ikeja Lagos, Nigeria.

\section{REFERENCES}

[1] Goto, Y., 1971, "Cracks formed in Concrete around Deformed Tension Bars." J. Am Concr. Instit Proc., Vol. 68, pp. 244-251.

[2] Yu Lakhtin, 1988, Engineering physical metallurgy and heat treatment, Mir publishers, Moscow, Russia, pp. 71-78. 
[3] ASTM: Annual Book of ASTM Standards, Part 4 (Standards for Deformed Steel Bar - A61572, A616-72, A617-72, Philadelphia, American Society for Testing and Materials 1973, pp. 684-99.

[4] Llwellyn, D. T., 1992, "Low-carbon structural steels." steels, metallurgy and applications, pp. 64-119.

[5] Nikolau, J. et al, 2003, "Microstructure and Mechanical Properties after heating of reinforcing 500MPa Weldable Steels." Journal of Construction and Building Materials, Vol. 18, pp. 243-254.

[6] Vlad, C. M., 1986, "A comparison between the TEMPRIMAL and TEMPCORE processes for high strength rebars", $27^{\text {th }}$ Mechanical Working and Steel Processing Conference Proceedings, Iron and Steel Society, Vol.23, pp. 908-912.

[7] Tarsuro, et al, 2001, Microstructure and Mechanical Properties of hot rolled bars for machine use, pp.241-256.

[8] Oelmann, L.A. et al, 1983, The structure, properties and heat treatment of metals, Pitman Books, Great Britain, pp. 54-57.

[9] British Standards Specification: BS 4449, 1988, Carbon Steel Bars for the Reinforcement of Concrete, pp. 4-8.

[10] Sahajwalla, et al, 2006, "Influence of carbonaceous materials in slag-foaming behaviour during EAF steel making”, Journal of Iron and Steel Technology, Vol. 3, No. 2, pp. 54-63.

[11] Owens, G. W. and Knowles, P. R., 1992, Steel designer's manual, Blackwell Scientific Publications.

[12] Ghosh, P. K. et al, 2007, “The Development of a New Approach to Deoxidation of Molten Steel”, Iron and Steel Technology, pp. 96-104.

[13] Richard, S., 2001, "Method for controlling the temperature of steel on a continuous hot rolling mill", Metallurgical Transaction B, Vol. 22, pp. 121-128.

[14] Obikwelu, D. C. N., 1987, "Metallurgical Considerations in the Optimization of Mechanical Properties of rolled products", Seminar paper presented at the Metallurgical and Research Department, Delta Steel Company, Aladja, Warri, Nigeria.

[15] Young Kil, 1988, "Quest for competitive clean steel”, Steel Technology International, pp.118-121.

[16] Breedijk, T., 1976, "Weldable Bar for used in Reinforcing Concrete", Patents Citation USPTO.

[17] Raja, B. V. et al, 2005, "The use of sponge iron in electric arc furnace", Steel Times International, Vol. 29, No. 3, pp. 17-22.

[18] Dieter, E. George, 1976, Mechanical Metallurgy, McGraw Hill International Edition, Materials Science and Engineering Series, $3^{\text {rd }}$ Edition, pp. 184-206

[19] Alberto Augusti, 1995, "Direct Rolling of Slabs and Round Bars", Metallurgical and Plant Technology International, No. 3, pp. 60-64.

[20] Katsuma, Y. et al, 1988, "A new process for hot direct charging", steel technology international, pp. 231-232. 
[21] Lundberg, S. E., 1997, "Roll-pass design: The key function in control of shape, dimension and mechanical properties of hot rolled products", Scandinavian Journal of Metallurgy, Vol. 26, No. 3, pp. 102-114.

[22] Pauskar and Shivpri, 1999, Microstructure and mechanics in the modeling of hot rolling of rods, CLEP annals.

[23] Appleton, E. and Summad, E., 2000, $2^{\text {nd }}$ European Rolling Conference at AROS Congress Centre, Sweden, May 24-26.

[24] Bergstrom and Hallen, 1982, "An Improved Dislocation Model for Stress-Strain Behaviour of Polycrystalline $\alpha$-iron", Materials Science and Engineering, No. 1, Issue 55, pp. 49-61.

[25] Balogun, S.A., Esezobor, D.E., Adeosun. S.O., 2007, "Stress Variation in Deep Drawn 1017 Aluminum Alloy." Journal of Materials Engineering and Performance. ASM International. Vol. 16, No. 6, pp. $766-774$

[26] Salvador, G., 2001, "Endless Rolling and Welding Process for Wire and Bar mills", Metallurgical Plant and Technology International, No. 3, pp. 46-53. 